\title{
The pronunciation of identical consecutive letters in the Yemenite Jewish tradition
}

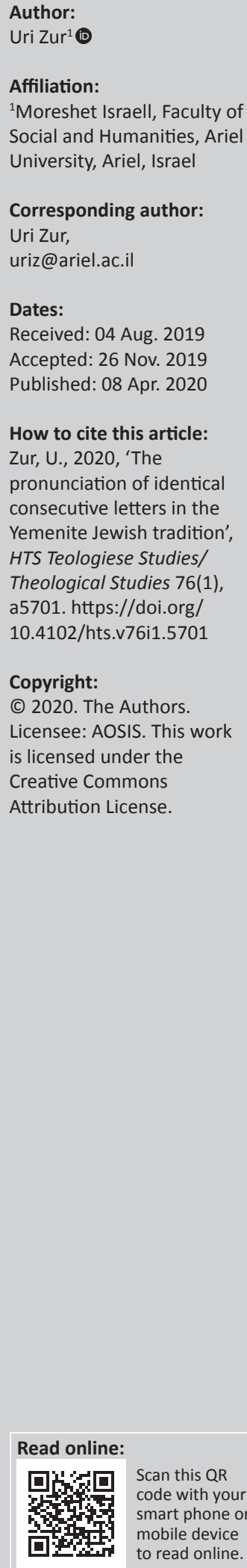

This article examines the pronunciation of identical consecutive letters in the Yemenite Jewish tradition, with a basic comparison with the pronunciation of identical letters in other present-day traditions. It is notable that in the Yemenite tradition also there are differences of opinion as to the pronunciation of these letters as a result of the effect of their pronunciation in other present-day traditions. In this article, we present the fundamental views with regard to the pronunciation of identical consecutive letters as well as their possible pronunciations in light of the grammar rules evident from the grammarians. The article does not purport to provide a historical, developmental or chronological investigation of the grammar rules; rather, it focuses on one specific topic involving the pronunciation of identical consecutive letters in the Yemenite tradition.

Keywords: Bible; pronunciation; Shvana'-nah; identical consecutive letters; Yemenite Jewish; vocalisation.

\section{Introduction}

Many important studies have been conducted on the pronunciation tradition of Yemenite Jews, including the pronunciation of the shvana ' (Morag 1956, 1957) as well as criticism of these studies (Kutscher 1966). The current article focuses on the pronunciation of the shva in the first of two identical consecutive letters which appear in one word, according to the Yemenite tradition (in San 'aa and the region), examining whether this utilises a shvana 'or shvanah. There are different views based on grammar rules regarding the rules of shvana ' (Morag 1963:135-149, 1969:173-181), a vocalisation that appears as two dots under a letter, for instance, the shva under the letter alef ( $)$.

\section{The general view}

The general customary view regarding two identical consecutive letters is supported by one of the main grammar rules, whereby whenever the first of any two identical consecutive letters bears a shva, this shva is a shvana '(Ashkenazi 1539:ch. 3), even if it is preceded by a short vowel (a term used for one of the five types of vowelisation defined as short vowels). In such case, then a meteg (a small perpendicular line below the letter) will appear in the letter preceding the letter with the shva in order

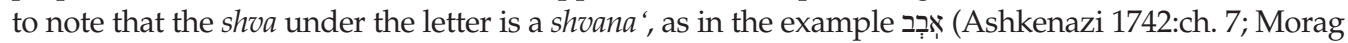
1963:137-139, 140; Ya 'akov 2014:68; Yeivin 1990:159).

The reason for this is that if the first of the identical consecutive letters bears a shvanah, then when articulating, it would assimilate with the second of the identical letters and they would not be pronounced separately, although ideally each letter should be pronounced and vocalised separately (Gamlieli 2006:30).

The following are several examples of this rule: the shva in the word 'רְְִִִ (Gn 14:7). In this word, the letter het bears a short vowel (patah) and below it there is a meteg(n). Therefore, the shva under the letter tzadi (צ), the first of the identical letters, is a shvana ' (Morag 1963:144). For this reason, the letter tzadi should be pronounced and vocalised in such a way that it is heard explicitly, as in the transcribed example: be-ha-za-zon.

Another example is the word 'Exכְכִים' (Ex 25:20). Below the first letter samekh, at the beginning of the word, there is a meteg(o), therefore the shva under the letter khaf (כ), the first of the identical letters, is a shvana: For this reason, the letter khaf should be pronounced and vocalised as in the transcription: so-kha-khim (Berggrün 1949:171-172).

Also, there is another word 'צ̦:רִרים (Nm 25:18). Below the first letter tzadi in the beginning of the word there is a meteg (ษ), and therefore the shva under the first resh ( $\urcorner$ ) of the identical letters is a shvana: For this reason, the letter resh should be pronounced and vocalised as in the transcription: 
zo-ra-rim. Finally, this is also true of the last example, the word 'Ps 146:1). The first letter hey in the beginning of the word bears a small vowel (patah) and has a meteg below it (i⿱ $)$. Therefore, the shva under the letter lamed (?), the first of the identical letters, is a shvana', and hence the letter lamed should be pronounced and vocalised as in the transcription: ha-la-li.

As stated, the shva under the first of the identical consecutive letters is a shvana ' (literally, mobile shva) and its function is to facilitate motion (Morag 1963:164) in the first letter in such a way that each of the two identical letters is pronounced and heard clearly and the identical letters are not assimilated when articulated.

Of course, other words are also there that resemble the examples presented above.

\section{Different views on the pronunciation of identical consecutive letters}

As a derivative of the rule mentioned above, we present the first view, whereby the first of the two identical letters cannot accept a shvanah; rather it will always bear a shvana. (Ashkenazi 1539:ch. 3; Berggrün 1949:174; Morag 1963:140), even if there is no meteg in the letter preceding the first of the identical letters (Ashkenazi 1539:ch. 3, 1742:ch. 7). (An example of this form of pronunciation is brought below in the second view on the word hineni).

According to the second view, the first of the two identical consecutive letters should be pronounced as a patah, designated by a small horizontal line under the letter, for instance: $\mathbf{x}$. The proponent of this opinion brings as an example the word hineni (with no reference) and explains himself as follows: the letter hey, in the beginning of the word, bears a short hirik, which is a small vowel ( $\pi$ ). The letter nun bears a shva (?) that appears to be a shvanah in the middle of a word following a small vowel (Yeivin 1990:159, 162). But this shva is not a shvanah, rather it is a shvana', because there is an 'iron rule', he says (one of the six iron rules), which determines that: 'Any shva coming on (meaning: under) the first of two identical letters is a shvana " (which is actually the first view) and should be pronounced as a patah under the letter (ฏ) (Ashkenazi 1539:ch. 3; Yeivin 1990:162-176).

The difference between the first and second views is manifested in the pronunciation of the first of the two identical letters. The proponent of the second view says that the word hineni, which he brought as an example above, should be read like this: hi-nani, and the first of the two identical letters should be pronounced as if written (a type of patah under the first nun of the two identical letters): hi-na-ni (Yada 'ei 2018:18). According to the first view, the word hineni should be pronounced with a shvana 'in the following form as in the transcription: hin-ne-ni or hi-ne-ni (Berggrün 1949:171).

However, the proponent of the second view contradicts himself further when he states the rules for shvana ' and writes:
'A shva that appears in the first of two identical consecutive letters is normally a shvana" (Yada 'ei 2018:62). He added to this rule (which is actually the rule mentioned at the beginning of his words) the word 'normally'. Meaning that he notes and is aware of the fact that this is not always so. Namely, the first of the two identical consecutive letters will not always bear a shvana', rather there are exceptions, such that even according to him this rule cannot be defined as an 'iron rule'.

Further on, he brought other examples in support of his words, but it is notable that none of these included the word hineni, as he states that it should be pronounced as if written: hi-na-ni. This is not surprising, as the word was never pronounced $h i-$ $n a-n i$ in the Yemenite tradition, as he determines, and this word was never heard to be vocalised in this form in this tradition. Moreover, there are other words with identical consecutive letters that were never pronounced in the Yemenite tradition as he proposes (these will be brought below).

A third view accepts the rule espoused by the first view, but in the Yemenite tradition this rule is not considered an 'iron rule' (Berggrün 1949:173, n. 3; Kimhi 1966:71b, n. 1) as there are many examples of words that are exceptions (which will be presented below). Namely, when there are two identical consecutive letters in the middle of a word, the first letter will not always be pronounced with a shvana', rather with a shvanah (Berggrün 1949:171, n. 4, 172; Morag 1963:139, 143), with the identical letters assimilating with each other when articulated, such that these many examples in fact undermine the credibility of this rule.

In addition, some grammarians even refute this rule explicitly. The first grammarian wrote as follows (Ibn Ganach 1964):

Know that two identical letters when they are in proximity in one word and the first is naha (i.e. the vowelization of the first of the two identical letters is a shvanah) may assimilate with [each] other ... and some articulate this letter (with the shvanah) and do not assimilate it ... and strong proof that this is correct (to assimilate the identical letters when the first bears a shvanah) is the warning by the late Sages that every two identical letters that occur thus in kri'atshema should be separated, such as bekhollevavkha (Dt 6:5) (Tobi 2010:246) ... va-avadtemmehera (Dt 11:17) and this is [a] clear proof that separation is preferable to assimilation in kri'atshema only. And when separation is better, assimilation is not prohibited but is merely less worthy. Furthermore, the uniqueness of kri'atshema in this matter proves that it was permitted elsewhere, and that assimilating is possible in all these words, even when the cantillation note sometimes separates the two identical letters ... (pp. 251-252)

This indicates clearly and simply that in a case of two identical consecutive letters, the first can bear a shvanah rather than a shvana' (Morag 1963:139) and the two identical letters can be pronounced as one, that is, either assimilating with each other as though the word was written with one letter or not doing so.

According to the grammarian cited above, if we relate to the previous example, that is, the word hineni brought above in 
the second view, it should be pronounced hi-ni (Morag 1963:145, n. 1; Yeivin 1990:159, 162) while assimilating the letters as though it was written with one ' $n$ ' (nun) (or without assimilating, and then it would be pronounced hin-ni and the shva is a shvanah), rather than with two ' $n s^{\prime}$ (nun). This, because the letter hey that precedes the identical letters bears a hirik (?!) considered a small vowel and therefore the shva in the first of the identical letters (!) bears a shvanah, rather than a shvana : Therefore, the word should not be pronounced hi-ne-ni and there is no need to vocalise the two ' $n s^{\prime}$ (nun) in this word.

According to the grammarian cited above, this is a proof that the first of two identical letters can bear a shvanah rather than a shvana' (Morag 1963:139) (in contrast to the rule in the first view and to the second view) and the letters can be assimilated as though they are written with one letter and not two identical letters, and there is no need to pronounce and vocalise each of the two identical letters.

The second grammarian wrote as follows: 'And when two identical letters are written in one word ... and when they are preceded by a small vowel, they are assimilated with each other and the reading of each is not separate, rather they are both read as one, with the letters assimilating. Examples

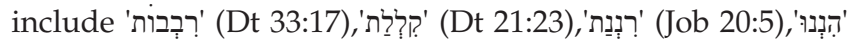

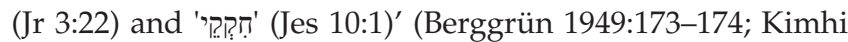
1966:71b; Morag 1963:139, 144; Ya 'akov 2014:69).

According to the second grammarian as well, if a small vowel appears in the letter that precedes the identical letters, the two identical letters should not be vocalised separately because the shva under the first of the two identical letters is a shvanah, and not a shvana', rather the two identical letters are to be assimilated and pronounced as one (Berggrün 1949:173). This proves that the first of the two identical letters can bear a shvanah, rather than a shvana ' (in contrast to the rule in the first view and to the second view) and that the letters can assimilate with each other as though written with one letter rather than two identical letters, and it is not necessary to pronounce and vocalise each of the two identical letters.

These two grammarians agree that the first of the two identical letters bears a shoanah. The difference between them is that the first grammarian brings two options for pronouncing the first of the two identical letters, assimilating the identical letters, as in hi-ni, or not assimilating them, hin-ni. The second grammarian only brings one option of pronunciation, assimilating the identical letters, as in hi-ni (Gamlieli 2006:31).

We refer to the examples of the second grammarian brought in his commentary, which clearly illustrate his words. (All the examples of the identical letters below, where the first of the two identical letters bears a shvanah, are presented in the assimilation method.) The word 'רְבְוֹ' should be pronounced ri-vot - assimilating (Berggrün 1949:173) as though written with one ' $\mathrm{v}$ ' (ri-vot), rather than ri-ve-vot, and the other ' $\mathrm{v}$ ' $(-v e-)$ should not be pronounced and vocalised, as the identical letters are preceded by a letter with a small vowel
(?) and therefore the first of the two identical letters (?ִ ) bears a shvanah rather than a shvana:

This explanation is also valid for the other examples brought by the second grammarian and we note here only the pronunciation of the words he brings as an example, such as

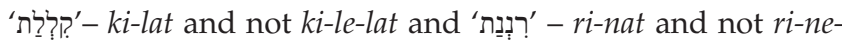

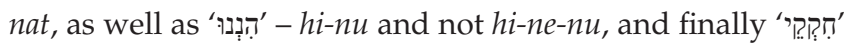
- hi-kei and not hi-ke-kei (Berggrün 1949:173-174).

In light of the third view, the first view that sets the rule that in any two identical consecutive letters where the first of the identical letters bears a shva, this shva will always be considered a shvana', is not only inaccurate but is refuted by the two grammarians mentioned above. In fact, this rule is a variable rule. Therefore, it cannot be considered an 'iron rule' similar to other 'iron rules' (Berggrün 1949:174) that determine, for example, that a shva at the beginning of a word is always a shvana', or that a shva in an accentuated letter in a certain word is always a shvana', or that when there are two consecutive shvas in a certain word, the second is a shvana (Ashkenazi 1539:ch. 3; Breuer 2009:280-288; Ya 'akov 2014:68; Yeivin 1990:177).

This rule is not only a variable rule (Morag 1963:142) but rather also a conditional rule. If there is a meteg under the letter preceding the identical letters, then the shva is a shvana (Berggrün 1949:173-174; Morag 1963:137-140; Ya 'akov 2014:68), as in the examples brought above in the 'Introduction' section. If there is no meteg in the letter preceding the identical letters and the identical letters are preceded by a small vowel, the shva in the first of the identical letters is a shvanah (Berggrün 1949:173; Morag 1963:138-139, 141, 144; Yeivin 1990:159, 162). However, according to the first view whereby even if there is no meteg in the letter preceding the identical letters the shva will always be a shvana - this is not always true, not only according to the two grammarians cited above but also according to the following examples.

The following are several biblical examples that refute the first and second views and support the third view. Firstly, we relate to the word hineni brought as an example (with no reference) in the second view; we shall present an example from the scriptures and examine its manner of pronunciation in the Yemenite tradition (Tobi 2010:239-268).

This word appears many times in the scriptures. As one example we relate to the word hineni (Gn 6:17) in the Pentateuch. As mentioned above, the letter hey preceding the identical letters bears a hirik, considered a small vowel, and the preceding letter has no meteg (ה̄). It has two identical consecutive letters and the shva under the first of the identical letters is pronounced as a shvanah (ग) (Morag 1963:138-139, 144-145; Yeivin 1990:159, 162) as follows: hi-ni, where one of the identical letters is assimilated with the other when articulated as though there is only one ' $n$ ' (nun).

In the Yemenite tradition this word is not pronounced $h i-n a-n i$ with two 'ns' (nun), following the second view, and certainly 
not hi-ne-ni with two 'ns' (nun) or hin-ne-ni with three 'ns' (nun), following the first view, but rather following the third view that assimilates the identical letters as follows: $h i-n i$, as though only one ' $n$ ' (nun) is pronounced. Hence, there is no room to pronounce the identical letters neither as in the first nor as in the second view, rather as in the third view.

According to the pronunciation following the third view, only one of the consecutive identical letters in the word is pronounced and the other is assimilated, as the shva under the first of the identical letters is a shvanah (Morag 1963:139). The first of the identical consecutive letters is not vocalised as though it bears a patah - as in the second view. And the two identical letters are certainly not vocalised as in the first view or as though another identical letter is added to the two identical letters, yielding three consecutive identical letters, even if there is no meteg in the letter preceding the identical letters as in the first view.

The tradition of pronunciation following the third view is also implemented in the following words, and it is not possible to pronounce these words neither as in the first nor as in the second view, and in the Yemenite tradition these words were not pronounced in a manner following either of these two views.

Here are examples of the following words:

'ואברכְְך' (Gn 12:2) - The correct pronunciation in the Yemenite tradition follows the third view: wa-a-vo-ra-kho (Berggrün 1949:174-175), rather than wa-a-vo-ra-kha-kho as in the second view, nor va-a-va-rekh-khe-kha or va-a-va-re-khe-kha as in the first view.

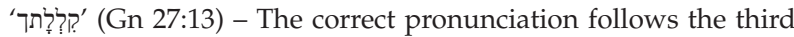
view: ki-lo-tha-kho (Berggrün 1949:173; Morag 1963:153, n. 1) and not ki-la-lo-tha-kho as in the second view, nor kil-le-la-te-kha or kile-la-te-kha as in the first view.

' ' ' (Gn 29:16) - The correct pronunciation follows the third view: $u$-lo-von and not $u$-la-lo-von as in the second view, nor $u l-l e-$ la-van or $u$-le-la-van as in the first view.

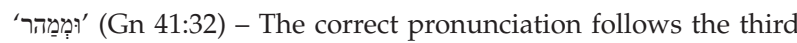
view: u-ma-her and not u-ma-ma-her as in the second view, nor um-me-ma-her or u-me-ma-her as in the first view.

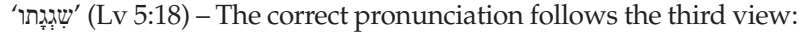
shi-gho-to (Morag 1963:153, n. 1) and not shi-gha-gho-to as in the second view, nor shig-ghe-gha-to or shi-ghe-gha-to as in the first view.

'מעַלְלָיכם' (Jr 4:4) - The correct pronunciation follows the third view: ma-'a-le-kham (Berggrün 1949:173, n. 2, 175) and not ma-'ala-le-kham as in the second view nor ma-'al-la-le-khem or ma-'a-lale-khem as in the first view.

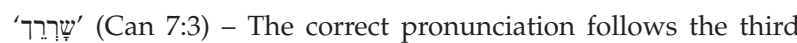
view: sho-rekh (Berggrün 1949:175, n. 3) and not sho-ra-rekh as in the second view, nor shor-ra-rekh or sho-ra-rekh as in the first view.

The following are several other words pronounced in the Yemenite tradition as in the third view presented above rather than following the first or second view, for instance:

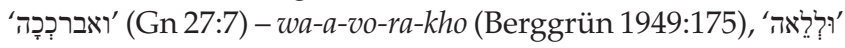
(Gn 31:4) - u-le-o, 'יברכְרכך' (Nm 6:24) - ya-vo-ra-kho (Berggrün

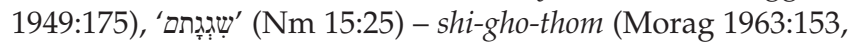
n. 1), 'ברכְ' (Dt 15:14) - be-ra-kho (Berggrün 1949:174-175),
'קלְלָתו' (2 Sm 16:12) - ki-lo-tho (Berggrün 1949:173; Morag 1963:153, n. 1), 'מעלרליהם' (Hs 9:15) - ma- 'a-le-ham (Berggrün

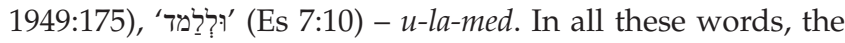
first of the two identical letters is pronounced with shvanah rather than shvana', even if there is no meteg in the letter preceding the identical letters (Morag 1963:139, 141). In light of the above, there is no room for the first and second views in the Yemenite tradition, rather place only for the third view.

Therefore, according to the Yemenite tradition, the rule for pronouncing identical letters, determining unequivocally that the shva in the first of the two identical letters is always a shvana' even if there is no meteg in the letter preceding the identical letters, as in the first view, should not be accepted (Morag 1963:139, 141). Rather this rule is, as stated, conditional and variable, and the shva in identical letters can certainly be a shvanah. In fact, the shva in identical letters was pronounced differently in the early generations until about five centuries ago, and was not necessarily a shvana ' until changing in all ethnic congregations (Berggrün 1949:174, 176). However, it did not change in the tradition of ancient Yemenite Jewry.

The suggestion to pronounce identical letters as in the second view should be completely refuted, as many words that have consecutive identical letters were never articulated in the Yemenite tradition as in this suggestion. Perhaps the proposal of pronouncing consecutive identical letters following this view could be relevant in modern Hebrew spoken at present but not in the Yemenite tradition.

Since we found in the ancient Yemenite tradition no tradition of pronouncing the demonstrated words as in the first or second view, we maintain the pronunciation following the third view, which is in fact the correct and accurate ancient pronunciation in the Jewish Yemenite tradition.

\section{Conclusion}

According to the third view, there are clearly situations of two consecutive identical letters, where if the first bears a shva, then the shva is a shvanah, rather than a shvana', and this rule varies according to the presence of a meteg in the letter preceding the letter with the shva. If there is a meteg in the letter preceding the letter with the shva, then the shva is a shvana'; if there is no meteg in the letter preceding the letter with the shva, then the shva can be a shvanah and the letters can be assimilated with each other and pronounced as one.

According to the first view, the shva in the first of the two identical letters is always a shvana ' even if there is no meteg in the letter preceding the identical letters - this view is inaccurate. Evidence of this was brought by the two grammarians who refuted this view, saying that the shva in the first of the two identical letters can certainly be a shvanah. Thus, also the argument in the first view, whereby if there is no meteg in the letter preceding the identical letters, then the first of the identical letters always bear a shvana ' is refuted by the words brought as examples above. In all these words, 
there is no meteg in the letter preceding the letter that bears a shva in the first of the two identical letters - and in the Yemenite tradition these are also pronounced with a shvanah rather than with a shvana ' (Gamlieli 2006:29-31).

The second view contains an inherent contradiction and, essentially, the proposed pronunciation of identical letters is refuted as well in light of that said by the two grammarians and also by the fact that in the words brought as examples above, the first of the identical letters cannot be pronounced as though written with a patah, as suggested in the second view.

Since the first and second views are not consistent with pronunciation in the Yemenite tradition, the pronunciation following the third view must be embraced exclusively as it, rather than either of the two other views, represents the most correct and accurate pronunciation of identical letters in the Yemenite tradition.

\section{Acknowledgements Competing interests}

The authors have declared that no competing interest exist.

\section{Author(s) contributions}

I declare that I am the sole author of this research article.

\section{Ethical consideration}

This article followed all ethical standards for a research without direct contact with human or animal subjects.

\section{Funding information}

This research received no specific grant from any funding agency in the public, commercial, or not-for-profit sectors.

\section{Data availability statement}

Data sharing is not applicable to this article as no new data were created or analysed in this study.

\section{Disclaimer}

The views and opinions expressed in this article are those of the author and do not necessarily reflect the official policy or position of any affiliated agency of the author.

\section{References}

Ashkenazi, E., 1539, Massoret ha-Massoret, Facsimile edn. [No. 117], Basel. Ashkenazi, E., 1742, TuvTa 'am, Issakhar B. Katz, Dyrenfurt.

Berggrün, N., 1949, 'Klal he shel R. eliyyahuBahur; perakim be-toledot ha-dikduk ha- 'Ivri', Lěšonénu 16(3-4), 169-179.

Breuer, M., 2009, 'Mobile and quiescent Šawa according to the rules of Biblical accentuation', in M. Bar Asher \& C.E. Cohen (eds.), Mas 'at Aharon, pp. 280-288, Bialik Institute, Jerusalem.

Gamlieli, E., 2006, Emrei Lashon, Zad, Rishon LeZion.

Ibn Ganach, Y., 1964, Sefer ha-Rikma, 22, 2nd edn., ha-Akademyah la-lashon ha- Ivrit, Jerusalem.

Kimhi, D., 1966, Mikhlol, Hoechheimer, Jerusalem.

Kutscher, E.Y., 1966, 'Yemenite Hebrew and ancient pronunciation', Journal of Semitic Studies 11(2), 217-225. https://doi.org/10.1093/jss/XI.2.217

Morag, S., 1956, 'Ha-sheva be-Hagiyatamshel Bnei-Teman', Lěšonénu 20(2), 112-134.

Morag, S., 1957, 'Ha-sheva be-Hagiyatamshel Bnei-Teman', Lěšonénu 21(2), 104-116.

Morag, S., 1963, The Hebrew language tradition of the Yemenite Jews, The Academy of the Hebrew Language, Jerusalem.

Morag, S., 1969, 'Semi-mobile ŠĚWA', in A. Shinan (ed.), Proceedings of the fifth world congress of Jewish studies, vol. 4, pp. 173-181, Refael H. ha-Cohen Press, Jerusalem.

Tobi, Y., 2010, 'The pronunciation of mobile Shevain ancient Yemenite tradition', in E. Hazan \& Z. Livnat (eds.), Mishnaic Hebrew and related fields studies in honor of Shimon Sharvit, pp. 239-268, Bar-Ilan University Press, Ramat-Gan.

Ya'akov, D., 2014, 'Two comments on the Shva in Yemenite language tradition', Carmillim 10, 67-78.

Yada 'ei, S., 2018, Ha-Ta 'am le-Ta 'amei ha-Mikra [Draft], Yada 'ei, Ashkelon.

Yeivin, I., 1990, 'Interchanges between vocalic Shewa and a full vowel in Genizah fragments of Piyyutim', in M. Goshen-Gottstein, S. Morag \& S. Kogut (eds.), Studies on Hebrew and other semitic languages presented to professor Chaim Rabin, pp. 159-177, Academon Press, Jerusalem. 